Paideusis

\title{
Imagination and Education (Kieran Egan and Dan Nadaner (Eds.))
}

\section{Sharon Bailin}

Volume 5, Number 2, 1992

URI: https://id.erudit.org/iderudit/1073350ar

DOI: https://doi.org/10.7202/1073350ar

See table of contents

Publisher(s)

Canadian Philosophy of Education Society

ISSN

0838-4517 (print)

1916-0348 (digital)

Explore this journal

Cite this review

Bailin, S. (1992). Review of [Imagination and Education (Kieran Egan and Dan

Nadaner (Eds.))]. Paideusis, 5(2), 39-43. https://doi.org/10.7202/1073350ar

(c) Sharon Bailin, 1992

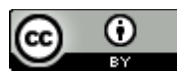

This document is protected by copyright law. Use of the services of Erudit (including reproduction) is subject to its terms and conditions, which can be viewed online.

https://apropos.erudit.org/en/users/policy-on-use/ 


\section{Review Essay}

\section{Kieran Egan and Dan Nadaner (Eds.), Imagination and Education (New York: Teachers College Press, 1988)}

\section{Reviewed by Sharon Bailin, Simon Fraser University}

In the introduction to Imagination and Education, the editors make the observation that "our educational systems at present are profoundly influenced by conceptions of education that ignore or depreciate imagination." If this observation is correct, then Kieran Egan is doing his part to remedy this lacuna in the three volumes under discussion here. ${ }^{1}$ What the three books have in common is a central concern with the nature of imagination, its role in thought, and its place in the educational enterprise.

Imagination and Education, edited by Egan jointly with Dan Nadaner, is a collection of fourteen papers emanating from a variety of disciplinary perspectives including analytic philosophy, phenomenology, history, literary criticism, cognitive and clinical psychology. The approaches taken to the subject reflect this disciplinary diversity from the admirable lucidity of Barrow's conceptual analysis to the poetic musings of Ted Hughes, from Hanson's careful philosophical argumentation to Shepard's case study analyses from Golomb's descriptive account of the development of children's art to Sturrock's entertaining evocation of Romantic literature.

The authors claim in the introduction that a "clear concept of the imagination is needed if the decline of imagination in the curriculum is to be halted." Yet, no one concept emerges from this particular volume. Rather, the book offers a range of conceptions, some complementary and some contradictory, paralleling the diversity of approaches taken by the various authors. Imagination is viewed variously as metaphorical thinking, nondiscursive thinking, visual imagery, fantasy, thinking which deals with what is not, thinking which sees beyond the ordinary, an invisible mental event, and a cultural event. One author even denies that imagination is an entity at all, but views it, rather, as the quality of unusual and effective conception.

One matter upon which all the authors are in agreement is that imagination is vitally important in education. Yet, from this range of conceptions of imagination, there emerges, not surprisingly, a similar range of recommendations regarding precisely how education should deal with the imagination. For example, Barrow emphasizes the importance of understanding and competence within specific contexts, Shepard suggests free, direct, nonverbal exploration of the natural world, Walker emphasizes musical expression, Nadaner advocates education in the arts, Matthews extols the virtues of philosophical literature, Weininger promotes imaginative play, and Egan favours stories.

That there is no one unified vision of the imagination emerging from this volume need not be seen as a flaw in the book. The editors celebrate its multiplicity, suggesting that perhaps the imagination is, itself, diverse. If imagination is, indeed, fostered by an exposure to a multiplicity of views, as several of the authors suggest, then this book certainly provides stimulus to our imagination in thinking about imagination.

Egan's own contribution to the volume, "The Origins of Imagination and the Curriculum," deserves special attention as it is an abridged version of the 
arguments he presents in great detail in Primary Understanding (1988) and in a form directed specifically to teachers in Teaching as Story Telling (1988). Hence, it is to these volumes that I now turn.

Primary Understanding is the first of a proposed four volume work, each volume of which will describe a program of education at a particular stage of development. Each of these stages, according to Egan, is characterized by a distinct type of understanding, the various understandings layering one upon another to result, ultimately, in an educated consciousness. The present work deals with the primary form of understanding characteristic of the early years which Egan refers to as mythic understanding.

One of the claims upon which Egan builds the rest of his analysis is that both epistemological and psychological perspectives are incomplete in their attempts to prescribe educational practices. The epistemological approach fails to give sufficient acknowledgment to the characteristics of the student while the psychological approach fails sufficiently to take into account the features of the disciplines of knowledge into which the student is to be initiated. Egan tries to find a middle ground between psychology and epistemology in the notion of sense-making, suggesting that our "bonnes à penser" or sense-making techniques are products of both nature and culture.

The sense-making techniques which Egan has in mind here are of orality. $\mathrm{He}$ argues that children, like members of non-literate cultures, should be seen not simply as lacking in literacy, but rather as possessing their own techniques for sense-making the "bonnes à penser" of orality including the poetic techniques of rhythm, rhyme, and metaphor, a sense of participation in the world characterized by immediacy, wonder, and energetic emotional engagement, and techniques of explanation and classification centred on the story form and binary opposites. These techniques Egan views as the bases of imagination and, thus, contends that we should pay attention to minimizing their loss as well as to maximizing the gains which are a part of education in a literature culture. Their preservation is important both for its own sake in terms of the meaning and even ecstasy it provides, and as a foundation for further learning since the rationality which is one of the goals of education is not the antithesis of imagination, but is based upon it.

On the basis of this analysis, Egan details a number of errors he believes have been committed by contemporary educational practice with young children. These include the failure to recognize the importance of fantasy, the underestimation of young children's capacities of understanding, particularly of profound abstract concepts such as love, hate, and oppression, and the neglect of the affective dimension.

To remedy these problems, Egan proposes an alternative primary curriculum. Such a curriculum is outlined in Primary Understanding but is described in much greater detail in Teaching as Story Telling. The goal of this curriculum is to develop a sense of magic and ecstasy in inquiry, but still accommodate the academic disciplines. Central to its development is the use of the story form and of binary opposites. Egan argues that the story form is relevant not just to language arts but can be abstracted from particular stories and used to organize any kind of content in all areas to make it more accessible and meaningful to children. The story context allows the subject matter to be grasped imaginatively, thus overcoming the difficulty children experience with 
disembedded thinking. Stories also have an affectively engaging quality which helps make the material meaningful. Egan also advocates the organization of such stories around binary opposites, such as freedom versus oppression, or knowledge versus ignorance, so as to provide an initial grasp of the material with eventual mediation of the gradations in between. The curriculum he advocates removes the emphasis on the local, immediate, and trivial which he claims characterizes contemporary primary education.

Egan has presented us with an oeuvre in these volumes which provokes and excites, while challenging a good deal of conventional wisdom about education in general and primary education in particular. But it is a work which is difficult to evaluate, a point which Egan himself admits. Its claims are neither strictly empirical nor strictly conceptual but exist in a murky region between the two. Its case is circumstantial and suggestive rather than tightly argued, offering a novel configuration of existing information.

He paints an alternative picture for our consideration which has much to recommend it. It is refreshing in taking young children seriously both in their capacities and their work. It is salubrious in reminding us about the sense of magic and ecstasy, and of wonder which must be part of inquiry. It displays considerable originality in focusing on the losses which may be a function of education, particularly the loss of imagination, but it avoids the trap of glorifying fantasy and setting up the uncultured imagination as a model for adults. It aptly indicates the necessity for learning to be meaningful. And it rightly points out that rationality and imagination are not in conflict but are closely connected. Indeed, it is a desiccated concept of rationality which sees them as opposed. Finally, it is conveyed with wit and elegance which makes it pleasurable reading.

Nonetheless, one would need to ask some questions before being willing to transform entire educational systems solely on the basis of this vision. A prime concern in these works is the fostering of imagination across the whole range of areas with which education is concerned, yet the connection between the techniques of orality-such as rhyme and story form-and fostering of imagination in certain areas-for example, painting or mathematics-seems rather tenuous. It is difficult to see why the development of rhyme would help one to become a more imaginative mathematician, particularly if Barrow is correct in his contention that there is no general faculty or capacity of imagination.

Indeed, Egan rests the entire weight of primary education and a good deal more on these "bonnes à penser," moving from the fact that children (and oral cultures) use these techniques to claims that they are constitutive of the imagination, that they are at the roots of rationality, that they are fundamental to who we are, that the entire curriculum should be based on them. In making these moves, he acknowledges the possibility of committing the naturalistic fallacy, a problem that I am not sure he has been entirely successful in avoiding.

There are also questions with regard to story form and binary opposites. In making his case for the importance of oral sense-making techniques, he compares children to members of preliterate societies. Yet, for these societies, the purpose of the story form and its accompanying poetics of memory was to foster uncritical assimilation of the material. Might these modes of learning not have the same effect with children? Indeed, one might argue that one of the problems of contemporary society is the pervasiveness of story form (in the 
form of TV soaps, for example) and the resultant inability of people to transcend stories in order to think abstractly and rationally about the issues. It seems counterintuitive, therefore, to propose as central to the later development of rationality those forms which seem to undermine rationality and which seem all too ubiquitous.

The problem is especially acute since stories are to be constructed around polar opposites. Yet, the domination of oppositional thinking in society is a cause of concern (e.g., capitalism as good, communism as bad) and one of the desired outcomes of education is the development on the part of students of critical abilities which will lead to increased subtlety and discrimination in their thinking. Egan acknowledges the danger in having oppositions dominate for too long, but I would have to be convinced that promoting such thinking at this stage would not be counter-productive to more subtle thinking at a later stage. But for that argument I must wait for the next volume.

There is also problem regarding which story to tell since any situation could be construed into a great many different stories. In Teaching as Story Telling, Egan gives an example of how a unit could be build around the story of the supermarket as a wonderful achievement of humanity. But the story of a supermarket could equally be told as a story of corporate mergers and corporate profits. And portions of Canadian history could be (indeed, have been) told as the story of white Europeans discovering North America and subduing savages. Egan provides no criteria for deciding which story to tell, what kind of opposition to choose, or how to mediate the opposition. Yet, these choices are crucial to whether what transpires is educative or not. Teaching about communism and capitalism, in the hands of some teachers, could well become the story of the triumph of the virtues of capitalism over the evils of communism. That this is not what Egan has in mind is apparent from the details of his own communism/capitalism example which turns out to involve a subtle and complex analysis of the tensions between the notions of freedom and equality. It is not a simplistic opposition after all, and perhaps the concept of binary opposition is misleading in terms of what Egan actually intends. Certainly it is liable to much potential abuse.

Moreover, utilizing the concepts of freedom and equality to teach about communism and capitalism is an approach which could well be justified without any reference whatsoever to story form or binary opposition. This, together with the previous point, might lead one to wonder how tight the connection is between Egan's theoretical view and the actual recommendations for teaching and curriculum when seen in their concrete detail. Taking children and their abilities seriously, embedding information in meaningful contexts, making material affectively engaging, and fostering a sense of wonder at inquiry are all part of what outstanding teachers do already.

Whether Egan's theory can avoid the problems outlined above is still an open question which will not be resolved until we see what he envisions for education at subsequent stages of development. Egan claims throughout that the story form engages us because the beginning creates expectations which are not satisfied until the end. Our expectations for the rest of the series are high. Primary Understanding is just the beginning of the story. 


\section{Notes}

${ }^{1}$ Kieran Egan and Dan Nadaner (Eds.), Imagination and Education (New York: Teachers College Press, 1988); Kieran Egan, Primary Understanding (New York: Routledge, 1988); Kieran Egan, Teaching as Story Telling (London, Ontario: Althouse Press, 1986). 